\title{
Melioidosis in Sri Lanka: an emerging infection
}

\author{
E Corea, ${ }^{1}$ V Thevanesam, ${ }^{2}$ S Perera, ${ }^{3}$ I Jayasinghe, ${ }^{2}$ A Ekanayake, ${ }^{2}$ J Masakorala, ${ }^{1}$ TJJ Inglis. ${ }^{4}$ \\ Sri Lanka Journal of Infectious Diseases 2012 Vol.1(2):2-8 \\ DOI: http://dx.doi.org/10.4038/sljid.v2i1.3801
}

Key words: Melioidosis; Sri Lanka; Burkholderia pseudomallei

\begin{abstract}
Melioidosis, a pyogenic infection that presents acutely or as a chronic infection, is caused by the soil-associated bacterium Burkholderia pseudomallei. Infection is acquired by inoculation or inhalation and is more common in patients with underlying chronic disease. It is endemic in the tropical belt. Although Sri Lanka is not considered as a country where melioidosis is endemic, an increasing number of cases have been reported recently. Definitive diagnosis requires the isolation of $B$. pseudomallei in culture from clinical specimens. However, the laboratory diagnosis of melioidosis in Sri Lanka and other under-resourced countries is limited by a lack of familiarity with the bacterium and a lack of facilities to accurately confirm the identity of the isolate. It is highly likely that melioidosis is under-diagnosed in this country. There is a need to increase awareness of this infection among clinicians and clinical microbiologists and improve laboratory facilities for the selective isolation and accurate identification of B. pseudomallei. In addition, studies are needed to determine the epidemiology of melioidosis in Sri Lanka.
\end{abstract}

\section{Introduction}

Melioidosis is a bacterial infection caused by Burkholderia pseudomallei, a Gram-negative, oxidase positive bacillus. Clinical infection may range from an acute, fulminant septicaemia with a high mortality to a chronic, localized infection, characterized by abscess formation. Severe infection is more common in people with an underlying predisposition such as diabetes mellitus, renal disease, liver disease or alcoholism. B. pseudomallei is a soil saprophyte. Infection is probably acquired by inoculation or inhalation of contaminated soil and water. In endemic areas

\footnotetext{
${ }^{I}$ Department of Microbiology, Faculty of Medicine, University of Colombo, Sri Lanka

${ }^{2}$ Department of Microbiology, Faculty of Medicine, University of Peradeniya, Sri Lanka

${ }^{3}$ Teaching Hospital, Sri Jayawardenepura, Sri Lanka

${ }^{4}$ School of Pathology \& Laboratory Medicine, Faculty of Medicine, Dentistry and Allied Sciences, University of Western Australia and Department of Microbiology, PathWest Laboratory Medicine WA, Nedlands, Western Australia, Australia
}

Address for correspondence: Enoka Corea, Senior Lecturer, Department of Microbiology, Faculty of Medicine, P O Box 271, University of Colombo, Sri Lanka.Email address: enokacorea@ hotmail.com 
the incidence of melioidosis increases in the rainy season. Case clusters of melioidosis have been described. ${ }^{1}$

Melioidosis is endemic in the tropical and subtropical zones of South East Asia and northern Australia, between the latitudes $20^{\circ} \mathrm{S}$ and $20^{\circ} \mathrm{N} .{ }^{1}$ Thailand, Northern Australia, Malaysia and Singapore have reported large numbers of cases. The prevalence recorded varies from country to country (Northern Australia 5-10\%, ${ }^{1}$ Taiwan 2.8-5\%, ${ }^{2}$ Cambodia 16\%, ${ }^{3}$ Thailand 10-29\%, Malaysia $7.3 \%,{ }^{5}$ Singapore $0.2 \%{ }^{6}$ ). The true distribution of melioidosis probably extends beyond South East Asia and Northern Australia as reflected by case reports from South America, the Caribbean, Africa and the Indian subcontinent. ${ }^{1}$ Melioidosis is an emerging infection in India, with a reported prevalence of $7 \% .^{7}$ Sri Lanka, positioned between $5-10^{\circ} \mathrm{N}$, is situated in the endemic belt and has similarities in weather and environmental conditions with these countries. However Sri Lanka has been considered non-endemic for melioidosis. ${ }^{1}$

Risk factors for melioidosis include occupational exposure to surface water and mud, particularly through working in rice paddy fields. Areas where the forest has been cleared for irrigation and rice cultivation have been shown to favour the presence of the organism in Malaysia and Thailand. ${ }^{1}$ B. pseudomallei can be recovered readily from water and wet soils in rice paddy fields in endemic areas. ${ }^{8}$ Suitable environmental conditions for this pathogen prevail in Sri Lanka.

\section{Melioidosis in Sri Lanka}

The first published report of melioidosis in Sri Lanka (and the Indian subcontinent) was in 1927 in a European tea broker resident in Sri Lanka, ${ }^{9}$ only sixteen years after the disease was initially described by Whitmore. One of the authors subsequently isolated B. pseudomalle $i$ from a splenic abscess in a cow. ${ }^{10}$ After a long, apparently disease-free interval, B. pseudomallei was isolated in 1994 from a lung abscess in a tourist returning to Holland from Sri Lanka. ${ }^{11}$ The first isolate of B. pseudomallei confirmed in a Sri Lankan clinical laboratory by modern methods was from a case of fatal sepsis in $2005 .^{12}$

In 2006/7, specimens of blood and pus from two patients, presenting with pneumonia with sepsis and sepsis associated with arthritis and skin abscesses respectively, yielded further isolates suspected to be B. pseudomallei. As the local laboratory was unable to confirm the identity of these isolates, advice was sought by internet search, and e-mail contact established with a public health reference laboratory in Western Australia. Advice on antibiotic management of the patients was obtained via e-mail and one patient was successfully treated. Subsequently, a portable molecular diagnostic laboratory was brought to Sri Lanka where preliminary molecular identification of the isolates was made. ${ }^{13}$

In 2008 two additional isolates were recovered. One was from a patient with brain stem encephalitis and the other from a post-mortem blood culture taken in a patient who collapsed and died at the emergency department after presenting with fever and diarrhoea. The local laboratories made a provisional identification based on clinical context, Gram stain and colony 
morphology, a positive oxidase reaction and resistance to gentamicin and colistin. The isolates were shipped to the reference laboratory for molecular confirmation of identity as $B$. pseudomallei by the use of multiple PCR probes, recA sequencing and gas liquid chromatography of bacterial fatty acid methyl esters. ${ }^{14}$

Table 1 Burkholderia pseudomallei isolates in Sri Lanka

\begin{tabular}{|c|c|c|c|c|c|c|c|}
\hline Isolate & $\begin{array}{l}\text { Presenting } \\
\text { location }\end{array}$ & Specimen & $\begin{array}{l}\text { Identity } \\
\text { confirmed }\end{array}$ & $\begin{array}{l}\text { Age/s } \\
\text { ex }\end{array}$ & $\begin{array}{l}\text { Occupation/risk } \\
\text { factors/exposure }\end{array}$ & $\begin{array}{l}\text { Clinical } \\
\text { presentation }\end{array}$ & Dutcame \\
\hline $1927^{9}$ & $\begin{array}{l}\text { Sri Lanka } \\
\text { (Ceylan) }\end{array}$ & Lung aspirate & $\begin{array}{l}\text { Gram stain } \\
\text { Culture } \\
\text { morphology } \\
\text { Guinea pig } \\
\text { inocumation }\end{array}$ & $\begin{array}{l}\text { 36y/ } \\
\text { male }\end{array}$ & European tea broker & $\begin{array}{l}\text { Lung } \\
\text { infection/septic } \\
\text { aemia }\end{array}$ & Died \\
\hline $1994^{11}$ & Holland & Lung aspirate & - & $\begin{array}{l}6 \text { 66/ } \\
\text { male }\end{array}$ & Tourism & $\begin{array}{l}\text { Brain abscess } \\
\text { Necratizing } \\
\text { pneumania }\end{array}$ & Survived \\
\hline $2005^{12}$ & $\begin{array}{l}\text { Sri } \\
\text { Jayawardenap } \\
\text { ura, Sri Lanka }\end{array}$ & Bload & API 2ONE & $\begin{array}{l}48 y / \\
\text { male }\end{array}$ & $\begin{array}{l}\text { Diabetes } \\
\text { Flouding }\end{array}$ & $\begin{array}{l}\text { Arthritis } \\
\text { Septicaemia }\end{array}$ & Dies \\
\hline 2006 & Peradeniya & $\begin{array}{l}\text { Pus, blood, } \\
\text { joint fluid }\end{array}$ & $\begin{array}{l}\text { Gram, Cultuгe, } \\
\text { PCR }\end{array}$ & $\begin{array}{l}58 y / f \\
\text { emale }\end{array}$ & $\begin{array}{l}\text { Building on abandaned } \\
\text { paddy field site }\end{array}$ & $\begin{array}{l}\text { Fever, multiple } \\
\text { subcutaneous } \\
\text { abscesses, } \\
\text { septicaemia }\end{array}$ & Survived \\
\hline 2007 & Peradeniya & Bload & Culture , PCR & $\begin{array}{l}2 \text { 26y/f } \\
\text { emale }\end{array}$ & Diabetes & $\begin{array}{l}\text { Fever } \\
\text { Pneumania }\end{array}$ & Died \\
\hline 2008 & $\begin{array}{l}\text { Sri } \\
\text { Jayawardenap } \\
\text { ura, Sri Lanka }\end{array}$ & Blond & Culture , PCR & $\begin{array}{l}\text { 58y/ } \\
\text { male }\end{array}$ & $\begin{array}{lr}\text { Diabetes, } & \text { renal } \\
\text { failure, } & \text { kidney } \\
\text { transplant } & \\
\end{array}$ & $\begin{array}{l}\text { Septic arthritis, } \\
\text { brain stem } \\
\text { encephalitis }\end{array}$ & Died \\
\hline 2008 & Colombo & $\begin{array}{l}\text { Postmartem } \\
\text { Bloud }\end{array}$ & Culture , PCR & $\begin{array}{l}45 y / \\
\text { male }\end{array}$ & Alcoholic & $\begin{array}{l}\text { Fever } \\
\text { Diarrhoea }\end{array}$ & Died \\
\hline
\end{tabular}

Since then, a further eleven historic and current, probable cases of melioidosis have been recorded by the first author (personal communication), from whom six clinical isolates, identified by preliminary screening to be $B$. pseudomallei are awaiting independent confirmation.

\section{Pitfalls in the laboratory diagnosis of melioidosis}

A diagnosis of $B$. pseudomallei infection requires both clinical suspicion and supporting laboratory evidence. The variety of clinical manifestations of infection makes melioidosis difficult to diagnose clinically. ${ }^{15}$ In most cases, the definitive diagnosis depends on the isolation and identification of $B$. pseudomallei from clinical specimens. ${ }^{16,17}$ Although B. pseudomallei will grow on most routine laboratory media using standard techniques, isolation rates mirror the availability of laboratory facilities and laboratory experience with this pathogen. ${ }^{16,17}$ 
All the Sri Lankan strains were isolated on primary culture of specimens from sterile sites. Isolation and identification of B. pseudomallei from non-sterile sites is difficult due to scanty growth which is outnumbered by contamination with commensal flora. ${ }^{15}$ For primary isolation from non-sterile sites, a selective agar for B. pseudomallei, either Ashdown's selective agar $(\mathrm{ASA})^{18}$ or an alternative selective agar ${ }^{19}$ has to be used in addition to blood agar and MacConkey agar. However, this requires a high degree of clinical suspicion as well as availability of these non-standard agar media.

Identification of B. pseudomallei in the laboratory can be difficult. A simple screening system involving Gram's stain, the oxidase reaction, colistin and gentamicin resistance and colony morphology on differential agar media followed by the use of the API 20NE substrate utilization kit has been recommended. ${ }^{20}$ More recently, a laboratory algorithm that combines preliminary identification tests with PCR-based methods has been described. ${ }^{14}$ However, it is likely that many isolates are dismissed as contaminants or misidentified, even in well equipped laboratories staffed by trained microbiologists as many microbiologists have no experience of this species, $B$. pseudomallei may be overgrown by commensals in specimens from non-sterile sites, colony morphology may be atypical and substrate utilization test panels such as API20E may give

misleading identification. ${ }^{14,15}$ In addition, in Sri Lanka, the majority of hospitals staffed with consultant physicians, surgeons and paediatricians to whom these patients would present do not have facilities for blood culture and are without the services of a consultant microbiologist. Therefore, it is very likely that infection with B. pseudomallei is under-diagnosed in Sri Lanka.

Identification of B. pseudomallei, in the cases reported from Sri Lanka (Table 1), hinged on the presence of experienced microbiologists and isolation from a sterile site. The Gram stain appearance i.e. Gram negative bacilli with densely staining ends and a pale middle (safety pin appearance) and a positive oxidase test (which may be delayed in some isolates), along with the typical antibiotic susceptibility pattern (resistance to aminoglycosides and colistin) were preliminary clues. The colony appearance of the different isolates was variable, ranging from smooth to dry, haemolytic to non-haemolytic on blood agar and lactose fermenting to lactose non-fermenting on MacConkey agar, illustrating the considerable inter-strain and mediumdependent variation in colonial morphology shown by this bacterium. ${ }^{16,19,20}$ However incubation of the plates at room temperature for one to four days resulted in wrinkling of the colonies and the typical colony appearance in all isolates. The sweet, earthy smell of the colonies was prominent in some isolates. The isolates were confirmed as B. pseudomallei by the reference laboratory.

\section{Reflections on the Epidemiology of Melioidosis in Sri Lanka}

It is highly likely that infection with B. pseudomallei is more prevalent in Sri Lanka than is currently perceived. Although only a limited number of cases have been reported, that does not exclude its presence as (i) melioidosis is a disease of mainly rural communities and probably goes undetected most of the time (ii) the disease can be rapidly fatal so that the patient dies before a diagnosis can be made (iii) clinical staff are unfamiliar with the disease (iv) blood culture facilities needed to recover B. pseudomallei are not universally available and (v) an isolate of $B$. pseudomalle $i$ would only be identified in a laboratory staffed by an experienced 
microbiologist and technical staff familiar with the bacterium. The thick pellicle growth that occurs in blood culture broth, the luxuriant, wrinkled growth on solid media and bi-polar staining on Gram stain will often lead to discarding of preliminary isolates as common environmental contaminants, as noted with the first Sri Lankan isolate in 1927. ${ }^{9}$ The importance of the microbiology laboratory in the diagnosis of B. pseudomallei infection is illustrated by the fact that more cases from Bangladesh, Vietnam, Burma and the Indian subcontinent are reported from returning travelers than from the indigenous population, reflecting low ascertainment of cases locally. ${ }^{1}$ Due to the lack of clinical laboratory support, melioidosis is very likely underdiagnosed in Sri Lanka and the rest of the South Asian region.

Published case reports are likely to represent only the visible "tip of the iceberg" of infection. ${ }^{8}$ Determining the true burden of disease caused by B. pseudomallei will require an increased awareness among clinicians of the presence and presentation of melioidosis, training of microbiologists and laboratory technologists to identify this bacterium in pure and mixed culture, supplying laboratories with the resources needed for selective isolation and preliminary screening for B. pseudomallei and establishing reference laboratory support for rapid confirmation of identity and accurate antimicrobial sensitivity testing.

Work with clinical specimens from patients suspected to have melioidosis and handling of $B$. pseudomallei cultures may be performed using BSL-2 practices. Work should be done in a class II biological safety cabinet by staff wearing gloves. ${ }^{21}$ As only a few microbiology laboratories in Sri Lanka have biological safety cabinets, working with this pathogen could pose a hazard to laboratory staff. Equipping laboratories to handle dangerous pathogens such as B. pseudomallei and Mycobacterium tuberculosis is, therefore, a priority.

Although serological tests are not useful in clinical situations, seroprevalence is likely to reflect exposure to $B$ pseudomallei on a population basis. ${ }^{1}$ The indirect haemagglutination assay ${ }^{21}$ (IHA) has been used extensively to determine the seroprevalence of exposure to $B$. pseudomallei. ${ }^{3,22,23,24}$ A study to determine the prevalence rate of antibodies to $B$. pseudomallei (prev. Pseudomonas pseudomallei) among hospital-associated patient groups in Colombo conducted in 1976, using an in-house IHA test described by Ileri $^{25}$ and standardized for use by the US Naval Medical Research Unit No. 2 (NAMRU-2), revealed a prevalence rate of antibodies to $B$. pseudomallei of $2 \%$. The report concluded that melioidosis was not a major public health issue in Sri Lanka. ${ }^{26}$ More than 30 years later the true burden of this disease is still to be established.

Epidemiological studies of melioidosis in Sri Lanka that would identify its geographical distribution, risk factors and clinical presentation are urgently needed. These should include carefully planned prospective sero-epidemiologic studies and targeted environmental bacteriologic testing. Genotyping of the isolates to identify the relationship to other isolates from across the globe will require collaboration with regional centres of excellence.

\section{Summary}


Melioidosis appears to be emerging in Sri Lanka, probably due to increased laboratory ascertainment. Improved and speedier clinical and laboratory diagnosis is needed to ensure early administration of appropriate therapy and improve prognosis. Clinical laboratory capability in Sri Lanka, including biosafety capability, should be enhanced. Further clinical and epidemiological studies are needed to identify the burden of melioidosis in Sri Lanka.

\section{References}

1. Cheng AC, Currie BI. Melioidosis: Epidemiology, Pathophysiology and Management. Clinical Microbiology Reviews. 2005; 18: 383-416. doi:10.1128/CMR.18.2.383-416.2005

2. Chen Y-S, Chen S-C, Wu T-R, Kao C-M, Chen Y-L. Seroprevalence of anti-flagellin antibody against Burkholderia pseudomallei in Taiwan. Japan Journal of Infectious Disease. 2004; 57:224-5. No doi.

3. Wuthiekanun V et al. Burkholderia pseudomallei antibodies in children, Cambodia. Emerging Infectious Diseases. 2008; 14: 301-3. doi:10.3201/eid1402.070811

4. Vuddhakul V et al. Epidemiology of Burkholderia pseudomallei in Thailand. American Journal of Tropical Medicine and Hygeine. 1999; 60: 458-461. No doi.

5. Strauss JM, Alexander AD, Rapmund G, Gan E, Dorsey AE. Melioidosis in Malaysia III Antibodies to Pseudomonas pseudomallei in the human population. American Journal of Tropical Medicine and Hygeine 1969; 18: 703-7. No doi.

6. Heng BH, Goh KT, Yap EH, Loh H, Yeo M. Epidemiological surveillance of melioidosis in Singapore. Annals of the Academy of Medicine, Singapore 1998; 27:478484. No doi.

7. Kang G, Rajan DP, Ramakrishna BS, Auken HM, Dance DA. Melioidosis in India. Lancet 1996; 347:1565-6. No doi.

8. White NJ. Melioidosis. Lancet. 2003;361:1715-22. No doi.

9. Denny CR, Nicholls L. Melioidosis in a European. Ceylon Journal of Science 1927; 2:37-40. No doi.

10. Nicholls L. Melioidosis, with special reference to the dissociation of bacillus whitmori. British Journal of Experimental Pathology 1930; XI;393-399. No doi.

11. Peetermans WE, Van Wjngaerden E, Van Eldere J, Verhaegen J. Melioidosis brain and lung abscess after travel to Sri Lanka. Clin Infect Dis 1999 28:921-922. No doi.

12. Jayasekara K, Perera S, Wijesundere A. Fatal Burkholderia pseudomallei septicaemia. Ceylon Medical Journal 2006;51: 69-70. No doi.

13. Inglis TJJ, Meritt A, Montgomery J, Jayasinghe I, Thevanesam V, McInnes R. Deployable laboratory response to emergence of melioidosis in central Sri Lanka. Journal of Clinical Microbiology 2008; 46: 3479-81. doi:10.1128/JCM.01254-08

14. Inglis TJJ, Merritt A, Chidlow G, Aravena-Roman M, Harnett G. Comparison of diagnostic laboratory methods for identification of Burkholderia pseudomallei. Journal of Clinical Microbiology 2005; 43:2201-6. doi:10.1128/JCM.43.5.2201-2206.2005

15. Inglis TJJ, Rolim DB, De Queiroz Sousa A. Melioidosis in the Americas. American Journal of Tropical Medical Hygeine. 2006;75:947-954. No doi

16. Finkelstein RA, Atthasampunna P, Chulasamaya M. Pseudomonas (Burkholderia) pseudomallei in Thailand, 1964-1967: Geographic distribution of the organism, attempts 
to identify cases of active infection and presence of antibody in representative sera. American Journal of Tropical Medicine and Hygeine 2000; 62: 232-9. No doi

17. Dance DAB. Melioidosis: the tip of the iceberg? Clinical Microbiology Reviews. 1991; 4: 52-60. No doi

18. Ashdown L. R. An improved screening technique for isolation of Pseudomonas pseudomallei from clinical specimens. Pathology 1979; 11: 293-7. No doi

19. Howard K, Inglis TJJ. Novel selective medium for isolation of Burkholderia pseudomallei. Journal of Clinical Microbiology 2003; 41: 3312-6. doi:10.1128/JCM.41.7.3312-3316.2003

20. Dance DAB, Wuthiekanun V, Naigowit P, White NJ. Identification of Pseudomonas hpseudomallei in clinical practice: use of simple screening tests and API 20 NE. Journal of Clinical Pathology 1989; 42:645-8. No doi

21. U.S. Department of Health and Human Services, Centers for Disease Control and Prevention, \& National Institutes of Health 2007. Biosafety in microbiological and biomedical laboratories (5th ed.) L. C. Chosewood \& D. E. Wilson (Eds.). Washington, DC: U.S. Government Printing Office. No doi..

22. Alexander AD, Huxsoll DL, Warner AR, Shepler V, Dorsey A. Serological diagnosis of human melioidosis with indirect haemagglutination and complement fixation tests. Applied Microbiology 1970; 20:825-833. No doi.

23. Chen W-T et al. Seroprevalence of melioidosis in diabetic patients in Taiwan. J Microbio Immunol Infect 2005; 38: 267-270. No doi.

24. Wuthiekanun V et al. Short report: Development of antibodies to Burkholderia pseudomallei during childhood in melioidosis-endemic northeast Thailand. American Journal of Tropical Medicine and Hygeine 2006; 74: 1074-5. No doi.

25. Ileria SZ. The indirect haemaglutination test in the diagnosis of melioidosis in goats. British Veterinary Journal 1965; 121:164-170. No doi.

26. Van Peenen PF, See R, Soysa PE, Irving GS. Seroepidemiological survey of hospitalassociated populations in Colombo, Sri Lanka. Southeast Asian Journal of Tropical Medicine and Public Health 1976; 1: 16-20. No doi. 